\title{
TRATAMENTO DE NÓDULOS AUTÔNOMOS E Ć́́sticos DA TIREÓIDE COM INEEÇAO INTRANODULAR DE ETANOL
}

\author{
Milena Braga-Basaria*, Marcus Adriano Trippia, Anderson Ravy Stolf, Cléo Mesa Jro, Hans Graf \\ Trabalho realizado no SEMPR-Serviço de Endocrinologia e Metabologia do Hospital de \\ Clínicas da Universidade Federal do Paraná, Curitiba, PR
}

RESUMO - 0 tratamento com injeção intranodular de etanol vem sendo utilizado há uma década como modalidade terapêutica eficaz no manejo de pacientes com nódulos da tireóide. Diversos estudos validaram o papel desta forma de tratamento em nódulos autônomos, císticos e, mais recentemente, nódulos frios benignos.

OBjEtIVo. Avaliar a efetividade da injeção intranodular de etanol no tratamento de nódulos císticos e autônomos da tireóide.

Métodos. 42 pacientes (26 pacientes com nódulos císticos e 16 com nódulos autônomos da tireóide) foram submetidos a tratamento com aplicação intranodular de etanol a $99 \%$, guiada por ultrasonografia e acompanhados por um período mínimo de seis meses.

RESULTADOs. Não observamos a ocorrência de complicações maiores durante ou após o tratamento, porém, na maioria dos casos, houve queixa de dor de leve a moderada intensidade e/ou desconforto após a aplicação do etanol. A maioria dos nódulos apresentou redução volumétrica significativa. A média de redução obtida para os nódulos autônomos foi de $50,3 \%$ e para os nódulos císticos, $69,3 \%$. Não houve diferença significativa entre os valores basais de T3 total, T4 total e TSH em comparação aos valores obtidos seis meses após o tratamento para 0 grupo de pacientes com nódulos císticos. 0 grupo de pacientes com nódulos autônomos apresentou redução nos valores séricos de T3 total e T4 total, assim como elevação dos níveis de TSH, confirmando a efetividade do tratamento.

Conclusão. A injeção intranodular de etanol é uma alternativa segura e eficaz no tratamento de nódulos autônomos e císticos da tireóide.

UnITERMOS: Nódulo da glândula tireóidea.Terapia. Etanol. Bócio nodular. Radioisótopos do iodo. Biópsia por agulha.

\section{INTRODUÇÃO}

A injeção intranodular de substâncias esclerosantes surgiu inicialmente como uma alternativa à intervenção cirúrgica e à ablação com iodo radioativo para os nódulos autônomos da tireóide e, posteriormente, para os nódulos císticos. A tentativa de realizar tratamentos menos agressivos estimuloua pesquisa de alternativas cada vez mais efetivas para este fim, evários agentes esclerosantes foram utilizados com resultados os mais variados.

A idéia de utilizar o etanol no tratamento de tumores sólidos e císticos em humanos foi inspirada em trabalhos experimentais em cães, nos quais se demonstrou a efetividade em produzir ablação renal e poupar o restante dos órgãos' ${ }^{\prime}$ Em seguida, passou-se a utilizar o mesmo tipo de álcool para humanos, inicialmente para tratamento de lesões renais ${ }^{2} \mathrm{e}$, posteriormente, para tratamento de diversas outras doenças ${ }^{3},{ }^{4}$. Em 1990, Livraghi et al. publicaram os resultados iniciais do tratamento

*Correspondência:

500W.University Picwy-Ap. 12-R

Baltimore, MD-EUA-21210

e-mail:bragamd@aol.com de nódulos autônomos da tireóide com injeção de etanol, baseado na experiência prévia do grupo no uso dessa substância no tratamento de carcinoma hepatocelular ${ }^{5}$ e outros tumores hepáticos e abdominais ${ }^{6}$, demonstrando se tratar de uma forma terapêutica segura ${ }^{7}$. Atualmente, a injeção intranodular de etanolé amplamente utilizada, com resultados excelentes e poucas complicações ${ }^{8,9}$.

Este trabalho tem como objetivo avaliar a eficácia do tratamento de nódulos autônomos e císticos da tireóide com injeção intranodular de etanol, assim como observar possíveis complicações decorrentes desta forma de tratamento.

\section{Métodos}

Participaram do estudo 42 pacientes com diagnóstico de nódulos autônomos ou císticos da tireóide que preencheram os seguintes critérios de inclusão: concordância com o estudo, nódulos únicos e seguimento por um período mínimo de seis meses após término do tratamento.

Para os pacientes com nódulos autônomos, foram utilizados os seguintes critérios de inclusão: nódulos únicos, caracterizados como benignos em punção aspirativa prévia e com cápsula bem delimitada ao ultra-som, ausência de calcificações, captação de iodo radioativo exclusiva pelo nódulo ou tecido adjacente com menor captação, TSH suprimido $(<0, \mathrm{I} \mathrm{mUI/}$ $\mathrm{ml}$ ) com T4 total normal (hipertireoidismo subclínico) ou elevado (hipertireoidismo clínico). Nenhum dos pacientes se encontrava em uso de antitiroideanos ou levotiroxina. O critério de cura utilizado para este grupo de pacientes foi de normalização dos níveis séricos de T3 total, T4 total e TSH.

Para os pacientes com nódulos císticos, os critérios de inclusão utilizados foram: nódulos únicos, caracterizados como benignos em punção aspirativa prévia, ausência de septações intranodulares, líquido facilmente aspirável e nódulos submetidos previamente a esvaziamento do conteúdo cístico e que apresentaram posteriormente recidiva. 0 critério utilizado para definir cura para os pacientes com nódulos císticos foi o de redução volumétrica maior que $50 \%$ do conteúdo líquido do nódulo, quando comparado ao volume pré-tratamento.

Todos os pacientes foram submetidos a punção aspirativa guiada por ultra-sonografia e 
estudo citopatológico do material aspirado para reforçar o diagnóstico de benignidade. Para os pacientes com nódulos císticos complexos (nódulos que apresentavam porção sólida e cística), procedeu-se também à punção guiada por ultra-sonografia da porção sólida do nódulo. Utilizou-se para a realização da ultra-sonografia e orientação da aplicação do etanol, aparelho da marca Siemens SL-250, equipado com transdutor linear de $7,5 \mathrm{mHz}$.

Os pacientes foram submetidos à ultrasonografia antes do início do tratamento eapós seis meses do término das aplicações. Particularmente, no caso dos nódulos císticos a ultrasonografiafoi realizada também um mês após o tratamento para observar possível recidiva. 0 volume de cada nódulo foi obtido através da fórmula para cálculo de estruturas elipsóides: diâmetrosântero-posterior X transversalX Iongitudinal $X \mathrm{p} / 6\left(\mathrm{em} \mathrm{ml}\right.$ ou $\left.\mathrm{cm}^{3}\right)$. Neste mesmo tempo, foram dosados T3 total (DPC Diagnostic Products Corporation, Los Angeles, CA, valores normais 86 a $187 \mathrm{ng} / \mathrm{dL}$ ); T4 total (DPC-Diagnostic Products Corporation, Los Angeles, CA, valores normais 4,5 a $12,5 \mathrm{mg} / \mathrm{dL}$ ); TSH (Serono, Roma - Itália, radioimunométrico, valores normais $0,43 \mathrm{a} 3,8 \mathrm{mUl} / \mathrm{ml}$ ), além de mapeamento cervical com ${ }^{|3|} \mid$.

O estudo foi aprovado pela Comissão de Ética do Hospital de Clínicas da Universidade Federal do Paraná. Anteriormente ao procedimento, todos os pacientes receberam informações sobre outras alternativas terapêuticas, assim como a técnica do procedimento a ser realizado e possíveis complicações. O estudo esteve de acordo com as recomendações da Declaração de Helsinki.

\section{Procedimento}

No momento da aplicação, solicitava-se ao paciente para que não movimentasse 0 pescoço e não deglutisse durante o período de introdução da agulha. O paciente era mantido em posição supina, com o pescoço discretamente hiperextendido. Os pacientes recebiam a cada sessão, após assepsia, uma aplicação local de I ml de xilocaína a $2 \%$, sem vasoconstritor, realizada com seringa de $3 \mathrm{ml}$ e agulha de $261 / 2 \mathrm{G}$. Utilizou-se álcool etílico (etanol) estéril a 99\% P.A. (Reagen, Rio de Janeiro), acondicionado em ampolas. Dez por cento da amostra utilizada foi submetida à análise bacteriológica com cultura, tendo por resultado ausência de crescimento de bactérias.

\section{Escleroterapia de nódulos autônomos}

Após a realização da anestesia local, introduzia-se lentamente a agulha acoplada em uma seringa com etanol a 99\%. Após injeção do etanol, aguardavam-se alguns segundos e retirava-se lentamente a agulha, evitando-se, desta maneira, a formação de um pertuito que permitisse o refluxo de álcool para a pele.

$O$ volume de etanol injetado por sessão variou entre $10 \%$ e $25 \%$ do volume do nódulo. Ocritério utilizado para interromper a aplicação foi o aparecimento de um aumento de pressão dentro do nódulo, determinado pela expansão do volume intranodular, limitado pela cápsula. As aplicações eram realizadas a cada 15 a 30 dias e o número total de sessões dependeu do volume injetado por sessão. O tratamento era interrompido quando o volume total de etanol injetado fosse semelhante ao volume do nódulo calculado antes do início do tratamento.

Após as sessões, cada paciente recebia a orientação de utilizar antiinflamatório nãohormonal se apresentasse dor importante.

\section{Escleroterapia de nódulos císticos}

Após anestesia, a agulha era introduzida até o centrodo nódulo. Após posicionamento adequado, aspirava-se quase totalmente o conteúdo cístico do nódulo, mantendo-se uma pequena porção (aproximadamente I ml), que permitisse avisualização do bisel da agulha mais nitidamente. Em seguida, a seringa era desacoplada e a acoplava-se com o etanol, injetando-se um volume correspondente em torno da terça parte do volume cístico calculado inicialmente, seguido de retirada da agulha. $O$ etanol injetado era mantido por um tempo de 15 minutos, seguido de reaspiração completa de todo 0 conteúdo líquido do interior do cisto.

Após a aplicação, cada paciente recebia também a orientação de usar antiinflamatório não-hormonal conforme descrito para os pacientes com nódulos autônomos, se apresentasse dor.

\section{Análise estatística}

Para análise dos dados quantitativos, foi utilizado o teste " $\mathrm{t}$ " de Student e para os dados qualitativos, o teste qui-quadrado. Para correlação entre dados, adotou-se o coeficiente de correlação produto-momento de Pearson. 0 nível de significância estabelecido foi de $5 \%$. Onde pertinente, os dados são representados como média + desvio padrão(DP).

\section{Resultados}

Quarenta e dois pacientes ( 26 com nódulos císticos e 16 com nódulos autônomos) foram submetidos a um total de I I I sessões de escleroterapia com etanol, guiadas por ultra-sonografia. Dos 42 pacientes, apenas quatro eram do sexo masculino (um paciente com nódulo autônomo, três com nódulos císticos). A média de idade para os pacientes com nódulos císticos foi de 43,5 anos ( 16 a 7 | anos) e para os pacientes com nódulos autônomos de 47,5 anos (I7 a 77 anos) (Tabela I).

\section{Nódulos autônomos}

Foram realizadas 72 sessões de injeção intranodular de etanol para os pacientes com nódulos autônomos. O número médio de sessões foi de $4,5 \pm 1,86$. A média do volume inicial encontrada para os nódulos autônomos foi de $20,91 \mathrm{ml}(D P=12,05 \mathrm{ml}$, variando de 2,2 a 53,4 ml). Após seis meses do término do tratamento, os nódulos apresentaram redução volumétrica média de $50,34 \%(p=0,0008)$ com volume final médio de $10,56 \mathrm{ml}(\mathrm{DP}=$ 6,97; variação de I,6 a 26, I ml) (Gráfico I).

Os níveis séricos de T3 total e T4 total apresentaram normalização após seis meses do tratamento na maioria dos pacientes (Tabela 2). Os níveis de T3 total apresentaram redução de $235,7 \pm 146,47 \mathrm{ng} / \mathrm{dl}$ para $136,5 \pm 43,56 \mathrm{ng} /$ dl; T4 total de $13,55 \pm 5,39 \mathrm{mg} / \mathrm{dl}$ para 8,22 \pm $3,0 \mathrm{mg} / \mathrm{dl}$ e os níveis de TSH apresentaram elevação de 0,38 $\pm 0,76 \mathrm{mUl} / \mathrm{ml}$ para I,44 \pm I,35 mUl/ml, apresentando normalização na maioria dos pacientes após seis meses de acompanhamento, porém com persistência em níveis suprimidos em três pacientes e em níveis indetectáveis em um paciente. Utilizando-se os critérios de cura estabelecidos para o estudo, $75 \%$ dos nódulos apresentaram cura total após seis meses de acompanhamento, enquanto que $25 \%$ apresentaram cura parcial (normalização de T3 total e T4 total, porém níveis séricos de TSHsubnormais).

Seis meses após o tratamento, todos os nódulos autônomos adquiriram aspecto hipoecóico à ultra-sonografia. Em alguns, pontos hipercóicos eram visualizados no interior dos nódulos, lembrando microcalcificações. Em nove pacientes, o mapeamento cervical $\mathrm{com}^{131} \mid$ previamente ao tratamento apresentava captação exclusiva pelo nódulo com supressão funcional da captação pelo restante do parênquima, enquanto que em sete pacientes, 
Tabela I - Aspectos gerais dos pacientes com nódulos autônomos e císticos

\begin{tabular}{lcc}
\hline & Nódulos autônomos & Nódulos císticos \\
Númerodepacientes & 16 & 26 \\
Idade(média \pm DP) & $47,5 \pm 19,23$ & $43,5 \pm 13,69$ \\
Sexo(F:M) & $15: 1$ & $23: 3$ \\
Númerodesessões & 72 & 39 \\
\hline
\end{tabular}

Tabela 2 - Sintomas relacionados ao tratamento nos pacientes com nódulos autônomos e císticos

Dor durante oulogo após aaplicação

Dorirradiada paranuca

Sensaçãolocal dequeimação

Tontura

Disfonia

Dor após 24 horas do tratamento

Desconforto cervical 24horasapós otratamento

Edemamusculaturacervical anterior

\begin{tabular}{cc} 
Autônomos & Císticos \\
$61 \%$ & $28,2 \%$ \\
$13,8 \%$ & $2,6 \%$ \\
$5,5 \%$ & $12,8 \%$ \\
$1,4 \%$ & - \\
$2,8 \%$ & $2,6 \%$ \\
$25 \%$ & $5,1 \%$ \\
$9,8 \%$ & $10,3 \%$ \\
$1,4 \%$ & - \\
\hline
\end{tabular}

Tabela 3 - Nódulos sólidos e císticos - avaliação hormonal antes e seis meses após o tratamento (os dados estão representados como valores médios \pm DP)

\begin{tabular}{lccc}
\hline Nódulos Autônomos & Pré-tratamento & Pós-tratamento & "P" \\
T3total (ng/dl) & & & \\
T4total(mg/dl) & $235,7 \pm 146,47$ & $136,5 \pm 43,56$ & 0,11 \\
TSH(mlU/L) & $13,55 \pm 5,39$ & $8,22 \pm 3,0$ & 0,15 \\
Nódulos Císticos & $0,38 \pm 0,76$ & $1,44 \pm 1,35$ & 0,02 \\
T3total (ng/dl) & & & \\
T4total(mg/dl) & $113,70 \pm 65,95$ & $127,54 \pm 30,80$ & 0,38 \\
TSH(mlU/L) & $9,00 \pm 1,39$ & $8,58 \pm 2,08$ & 0,39 \\
& $2,08 \pm 1,24$ & $2,44 \pm 1,99$ & 0,50 \\
\hline
\end{tabular}

Gráfico I - Nódulos autônomos: representação gráfica da redução volumétrica

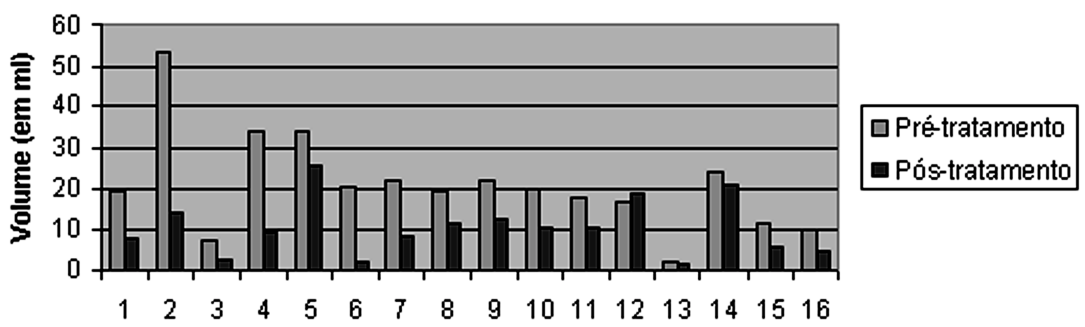

apesar do nódulo se apresentar hipercaptante, o restante do parênquima da tireóide apresentava discreta captação. Após o tratamento, todos os nódulos apresentaram redução da captação do radiodo em relação ao mapea- mento pré-tratamento, dois nódulos passaram a não captar o radiodo ("nódulos frios") enquanto que um nódulo passou a captar na mesma proporção que o restante do parênquima("nódulo morno").
A maioria dos pacientes com nódulos autônomos apresentaram queixas relacionadas ao procedimento durante ou logo após a aplicação do etanol (Tabela 3). Dor de leve a moderada intensidade logo após a aplicação com ou sem irradiação para a nuca e desconforto cervical com duração de mais de 24 horas após o procedimento foram sintomas mais frequentemente relatados. Uma das pacientes apresentou uma tumoração na região cervical anterior que se seguiu à terceira sessão de escleroterapia. À ultra-sonografia, observou-se edema muscular no trajeto formado pela agulha. Além do aumento de volume local, a paciente se queixou de dor de moderada intensidade e elevação discreta da temperatura corporal. Houve desaparecimento total do processo inflamatório após uma semana de uso de antiinflamatório não-hormonal e optou-se por interromper o tratamento. Quando analisamos o volume inicial do nódulo e 0 percentual de redução após o tratamento, encontramos uma fraca correlação (Pearson $r$ $=0,0189 ; p=0,471)$.

\section{Nódulos císticos}

Foram realizadas 39 sessões de injeção intranodular de etanol em 26 pacientes com nódulos císticos que preencheram os critérios de inclusão no estudo. $O$ número médio de sessões por paciente foi de $I, 5 \pm 0,94$, e a média de etanol injetado para cada nódulo foi de 7,06 (0,5 a $35 \mathrm{ml})$. 0 aspecto do líquido aspirado encontrado com maior freqüência foi achocolatado ( $81 \%, 21 / 26$ nódulos), sugerindo sangramento antigo, enquanto que em cinco nódulos observou-se líquido amarelo citrino.

$A$ redução volumétrica média foi de $69,3 \%(p=0,0004)$ (Gráfico 2). Vinte nódulos $(77 \%)$ apresentaram redução volumétrica maior que $50 \%$. Entre os nódulos que apresentaram redução menor, dois reduziram $40 \%$ a $49 \%$ em relação ao volume inicial do nódulo e três entre $15 \%$ e $25 \%$. Um dos nódulos apresentou recidiva para um volume semelhante ao volume prévio. Apesar deste nódulo ser bastante volumoso $(63,8 \mathrm{ml})$, a correlação encontrada entre o percentual de redução dos nódulos seis meses após o tratamento e o volume inicial do nódulo foi bastante fraca (Pearson $r=0,0398 ; p=0,1627$ ).

As médias dos valores séricos de T3 total, T4 total e TSH, antes e após o tratamento nos 


\section{Gráfico 2 - Nódulos císticos: representação gráfica da redução volumétrica}

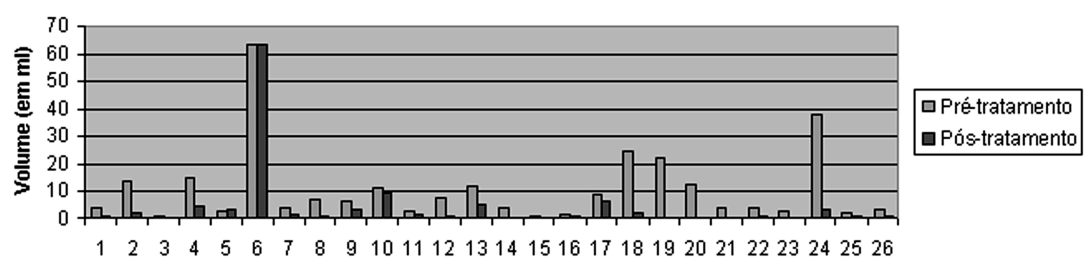

pacientes com nódulos císticos, estão demonstradas na Tabela 2. Não foram observadas diferenças significativas nos valores hormonais antes e após o tratamento para os nódulos císticos.

O sintoma mais freqüentemente referido pelos pacientes foi de dor local durante ou após o procedimento ou, menos frequentemente, queimação local (Tabela 3). A dor foi descrita na maior parte das vezes como sendo de leve a moderada intensidade. Poucos pacientes referiram dor ou desconforto cervical além de 24 horas após o procedimento.

\section{Discussão}

Em I I I sessões de aplicação intranodular de etanol, guiadas por ultra-sonografia, $75 \%$ dos pacientes com nódulos autônomos e $77 \%$ dos pacientes com nódulos císticos apresentaram cura, segundo os critérios estabelecidos pelo estudo, em um período de seguimento de seis meses.

Não observamos ocorrência de nenhuma complicação grave, apenas queixas de dor de leve intensidade ou de desconforto cervical, que foram referidas na maioria das aplicações. Apesar disso, nenhum paciente no estudo recusoua continuidade do tratamento. Papini etal..$^{10}$ relataram a ocorrência de dor local de intensidade moderada, porvezes com irradiação, em I00\% das aplicações. Em um estudo italiano multicêntrico, publicado em 1996, a dor foi relatada em $90 \%$ dassessões" $"$. Outros estudos observaram a presença de dor entre $22 \%$ e $30 \%$ dos casos ${ }^{9},{ }^{12}$. Já Martino et al. ${ }^{13}$ relataram a ocorrência de dor local ou irradiada em somente $3,9 \%$ de 305 sessões de injeção de etanol em nódulos autônomos. O cuidado de interromper a aplicação ao se observar resistência mecânica à introdução do etanol parece contribuir para reduzir estes sintomas, já que observamos maior freqüência de queixas quando ocorreu refluxo do etanol pelo pertuito formado pela passagem da agulha, acentuado pelo aumento de pressão formado dentro do nódulo autônomo. É provável que os estudos que encontraram incidências reduzidas destes sintomas tenham utilizado volumes menores de etanol por aplicação. Papini et al. ${ }^{10}$ utilizaram a injeção intranodular de xilocaína a $2 \%$, antes e após a aplicação do etanol, o que fez com quese reduzissem a intensidade da dor local ou irradiada, na opinião dos autores. Convém ressaltar que, coma introdução do anestésico, substituise em parte o volume do etanol injetado, reduzindo sua quantidade e, consequentemente, os sintomas decorrentes do refluxo do mesmo para a pele. $O$ uso do antiinflamatório nãohormonal logo após a aplicação nos pareceu ser mais efetivo em relação a redução da intensidade da dor quando comparado a aplicação local de xilocaína. Os demais sintomas imediatos e tardios observados em nosso estudo estão compatíveis com os relatados nos diversos trabalhos publicados ${ }^{11-15}$. No entanto, a ocorrência de edema muscular observado em uma das pacientes foi uma complicação inesperada. Esta paciente realizou vários movimentos de deglutição durante as aplicações que precederam o aparecimento do edema. É provável que isso tenha favorecido um refluxo maior do etanol para a musculatura cervical anterior, levando ao desencadeamento de um processo inflamatório importante no percurso da agulha.

A diminuição volumétrica dos nódulos autônomos já pode ser percebida logo após as primeiras sessões, e é decorrente das alterações degenerativas causadas pelo contato do etanol com o tecido intranodular. Segundo Bianchini et al. ${ }^{14}$, a redução volumétrica é mais pronunciada no primeiro e terceiro mês após a aplicação, apesar de poder ser observada até o sexto mês. Deacordo com o estudo realizado pelos autores, 19 nódulos autônomos apresentaram redução média de $49 \pm 20 \%$ no primeiro mês, $60 \pm 19 \%$ no terceiro mês, 67 $\pm 22 \%$ no sexto mês e $70 \pm 22 \%$ no primeiro ano de avaliação após o tratamento. Lippi et al." realizaram análise citopatológica de nódulos autonômos submetidos a escleroterapia com etanol e verificaram a presença de um material denso, homogêneo, com poucas células foliculares indicando a necrose coagulativa sofrida pelo tecido intranodular.

Goletti et al..$^{12}$ relataram uma discreta elevação dos níveis totais e livres de T3 e T4 durante a período de tratamento com etanol para os nódulos autônomos entre a terceira e quarta aplicações, refletindo o processo de destruição folicular, enquanto os níveis de TSH permanecem suprimidos, elevando-se progressivamente. Os níveis séricos de tireoglobulina também apresentam aumento significativo 15 minutos após a aplicação do etanol, atingindo seu pico máximo após seis horas. Monzani et al. ${ }^{8}$ realizaram uma análise cuidadosa dos níveis hormonais durante e após a escleroterapia e observaram uma elevação importante ( 3 a 4 vezes o valor basal) dos níveis de tireoglobulina durante o período de tratamento, além de discreto aumento dos níveis de T3 e T4 livres e normalização progressiva dos níveis de TSH em $81 \%$ dos pacientes com nódulos tóxicos. Observamos em nosso estudo, redução nos níveis séricos totais de T3 e T4 após seis meses do tratamento para os pacientes com nódulos autonômos hiperfuncionantes, porém a redução destes hormônios, quando comparados antes e após o tratamento, não teve significância estatística. Isto provavelmente ocorreu por muitos pacientes apresentarem níveis hormonais discretamente elevados, enquanto que outros apresentavam hipertireoidismo subclínico. Houve aumento dos níveis de TSH na maioria dos pacientes, permanecendo suprimido em um dos pacientes e abaixo do normal em outros dois na avaliação após seis meses. Por outro lado, os níveis séricos de T3 total e T4 total se encontraram dentro dos valores normais ao final da avaliação em todos os pacientes, à exceção de um caso onde os níveis de T3 total permaneceram discretamente elevados, porém com normalização dos níveis séricos de T4 total.

Martino et al..$^{13}$ relataram a ocorrência de 
aumento dos níveis de anticorpos antiperoxidase em um dos pacientes, com aparecimento de hipotireoidismo transitório. Elevações mais freqüentes foram observadas por Livraghi et al. ${ }^{7}$ e Monzani et al. ${ }^{9}$ (II,I\% e 2,5\%, respectivamente), sem a ocorrência de disfunção hormonal. Porém, a descrição de ocorrência de doença de Graves em um paciente após tratamento com injeção intranodular de etanol em um nódulo autônomo sugere que, provável material antigênico liberado pelas células foliculares após o tratamento possa desencadear imunogênese, com risco de desenvolvimento de patologias autoimunes em pacientes geneticamente predispostos ${ }^{15}$.

Os nódulos autônomos se apresentam de maneira variável ao mapeamento cervical com ${ }^{|3|} \mid$, após a escleroterapia. Na maior parte das vezes, existe recuperação (parcial ou total) da captação do radiodo pelo restante do parênquima. Ocasionalmente, onódulo esclerosado torna-se hipocaptante, como encontramos em dois casos em nosso estudo. A transformação para nódulo hipocaptante sugere a destruição total das células intranodulares autônomas, enquanto que a permanência de captação elevada pelas células nodulares em relação ao restante do parênquima pode refletir a inefetividade do tratamento. De fato, observamos um melhor resultado em termos de normalização de dosagens hormonais nos pacientes que sofreram destruição total do nódulo (aparecimento de nódulo frio ao mapeamento pós-tratamento). Por outro lado, Paracchi et al. ${ }^{16}$ não encontraram relação entre o aspecto do nódulo ao mapeamento $\mathrm{com}^{131} \mid$ e normalização dos níveis hormonais. 0 padrão hormonal encontrado foi semelhante em pacientes com nódulos completamente curados (desaparecimento do nódulo à cintilografia ou aparecimento de nódulo frio) e parcialmente curados (partes dos nódulos ainda podiam ser visualizados e havia recuperação funcional parcial pelo restante da glândula). Como existe um potencial de multiplicação pelas células foliculares autônomas, com possibilidade de proliferação das células que permanecem íntegras mesmo após a escleroterapia, o critério que deveria ser adotado para considerar "cura" após esta forma de tratamento seria a da transformação do nódulo para hipocaptante, garantindo assim a destruição total, ou quase total, das células foliculares. Seguimentos por períodos maiores que cinco anos, como o realizado por Monzani et al. ${ }^{9}$ com acompanhamento dos nódulos que permanecem com captação de radiodo, poderiam ser úteis em esclarecer a possibilidade de recidiva destaslesões.

Também para os nódulos císticos não foram observadas complicações graves em 39 sessões em 26 pacientes. Do mesmo modo, poucas complicações são descritas na terapêutica com etanol para as nódulos císticos, na maior parte das vezes restritas a uma discreta dor local ${ }^{17,19}$.Também observamos uma incidência menor de dor e desconforto nos pacientes tratados por nódulos císticos quando comparados aos pacientes com nódulos autônomos. Mais evidente, porém, foram as queixas relacionadas à intensidade do desconforto após a aplicação, pois os pacientes com nódulos císticos relataram apenas dor de leve intensidade (e na maior parte das vezes apenas desconforto) quando comparados com os pacientes portadores de nódulos sólidos autônomos (utilizamos como critério para esta conclusão, a necessidade ou não de utilização do antiinflamatório não-hormonal). Isto ocorre, provavelmente, por uma menor pressão dentro do nódulo cístico (que foi esvaziado previamente à injeção) em relação ao nódulo autônomo, a que pode ser constatado no momento da retirada da agulha, pois os nódulos autônomos, ao contrário dos císticos, apresentaram com freqüência refluxo do etanol para a pele através do pertuito formado pela agulha, - que seria responsável pela maior parte dos sintomas de dor logo após a aplicação.

Utilizando como critério de cura em nosso estudo a redução de $50 \%$ do volume basal para os nódulos císticos, observamos efetividade da terapêutica em $77 \%$, resultados parciais em $15 \%$, enquanto que um paciente não apresentou resposta ao tratamento após quatro sessões. Verde et al. ${ }^{20}$ compararam a aspiração simples com a escleroterapia com etanol e observaram maior percentagem de redução volumétrica e menor índice de recidiva no segundo grupo. Quando acompanhados a longo prazo, este mesmo autor observou efetividade na escleroterapia em $75 \%$ dos pacientes, utilizando o mesmo critério adotado por nós, e tendo apenas um caso de recidiva (3,12\%). Resultados semelhantes (cura de $72,1 \%$ e recidiva de $8,2 \%$ ) foram obtidos por Yasuda et al. ${ }^{21}$.

Alguns aspectos iniciais do nódulo cístico já sugerem uma maior possibilidade de recidiva, quando submetidos a aspiração simples ou a escleroterapia: cistos de maior volume, líquido de aspecto hemorrágico ou lesões complexas ${ }^{17,18}$. Em nosso estudo, não encontramos correlação entre o aspecto do líquido aspirado ou o volume inicial do nódulo e o sucesso do tratamento. Nódulos volumosos $(38,4 \mathrm{ml})$ apresentaram redução volumétrica significativa (92\%) após uma ou duas sessões de injeção intranodular de etanol, quando observados por um período mínimo de seis meses $^{19}$. Entre os pacientes que apresentavam inicialmente desvio de traquéia, houve uma melhora significativa já no primeiro mês após o tratamento.

Antonelli etal. ${ }^{22}$ descreveram a ocorrência de tireotoxicose de curta duração em um paciente com nódulo cístico submetido a injeção intranodular de etanol, com elevação nas concentrações de T3 e T4 livre. Também há relatos de ocorrência de elevação transitória dos níveis de T3 e T4 livre após esvaziamento de nódulos císticos da tireóide ${ }^{20}$. Monzani et al. ${ }^{9}$ realizaram avaliação hormonal três horas após escleroterapia em nódulos císticos e observaram aumento significativo dos níveis de tireoglobulina, porém sem mudança nas concentrações séricas de T3 e T4 livres e de TSH. Em nosso estudo, não observamos diferenças estatisticamente significativas nos níveis totais de T3 e T4 e de TSH após seis meses de tratamento.

\section{Conclusões}

Concluímos a partir do nosso estudo que a injeção intranodular de etanol, guiada por ultrasonografia, é um método eficaz no tratamento denódulos autonômos (tóxicos e pré-tóxicos)e císticos recidivantes da tireóide; dor ou desconforto locais são referidos por todos os pacientes, sendo mais comumente de moderada intensidade; não há complicações graves relacionadas a este tratamento; a redução volumétrica significativa se evidencia desde as primeiras semanas de tratamento e reflete um processo de degeneração intranodular rápida nos nódulos autonômos e um reacúmulo de líquido em quantidades muito menores ou ausente nos nódulos císticos; a progressiva normalização dos níveis de T3 e T4 totais e TSH nos pacientes com nódulos autonômos tóxicos ea redução da captação do radiodo pelo parênquima nodular, apontam também para a efetividade 
desta técnica. Não termos observado alterações hormonais ou de captação do radiodo no tratamento de nódulos císticos, também contribui para esta conclusão.

Em vista dos resultados que encontramos, que de uma forma geral coincidem com os descritos na literatura especializada, concluímos que este método deva ser incluído no arsenal terapêutico para os nódulos autonômos e císticos da tireóide, já que mostram ser igualmente eficiente às formas terapêuticas tradicionais (iodo radioativo e cirurgia para os nódulos autônomos e esvaziamentos repetidos e cirurgia para os nódulos císticos).

\section{Agradecimentos}

Os autores agradecem aos Drs. Eduardo Tomimori e Rosalinda Camargo pelos ensinamentos técnicos, aos Drs. Geraldo Medeiros-Neto, Doris Rosenthal e Antonio Carlos Campos pelas críticas valiosas recebidas durante a apresentação de parte deste trabalho e à Coordenação de Aperfeiçoamento de Pessoal de Nível Superior (CAPES) pela bolsa-auxílio.

Trabalho parcialmente realizado com bolsa-auxílio fornecida pela Coordenação de Aperfeiçoamento de Pessoal de Nível Superior (CAPES).

\section{SUMMARY}

TREATMENT OF AUTONOMOUS AND CYSTIC THYROID NODULES WITH INTRANODULAR ETHANOL INJECTION

Intranodular ethanol injection has been used for the past 10 years as an efficient modality for treating patients with thyroid nodules. Several studies have reported the success of this therapy in autonomous and cystic nodules and, more recently, in cold benign nodules.

PuRPose. To evaluate the efficacy of this therapeutic modality on the treatment of autonomous and cystic thyroid nodules.

Methods. 42 patients (26 with cystic and 16 with autonomous nodules) were treated with ultrasound guided intranodular $99 \%$ ethanol injection and followed for 6 months.

RESULTS. No major complications were observed during or after treatment, however, most of the patients reported slight to moderate pain and/or discomfort after the injection. Most of the nodules showed reduction after the treatment. Autonomous nodules had a mean reduction of $50.3 \%$ and cystic nodules of $69.3 \%$. No significant differences in pretreatment serum total T3, total T4 or TSH were observed among the patients in the cystic group. Patients in the autonomous group with hyperfunctioning nodules showed a decrease in serum total T3, total T4 and an increase in serum TSH levels, hence, proving the effectiveness of this therapy.

ConClusions. Intranodular ethanol injection is a safe and efficient treatment for autonomous and cystic nodules of the thyroid. [Rev Assoc Med Brasil 2002; 48(4): 335-40]

KEY WORDS: Thyroid nodule, Therapy, Ethanol. Goiter/nodules. lodine radioisotopes. Needle biopsy.

\section{ReFERÊNCIAS}

I. Ellman BA, Parkhill BJ, Curry III TS. Ablation of renal tumors with absolute ethanol: a new technique. Radiology 1981; 141:619-26.

2. Bean W. Renal cysts: treatment with alcohol. Radiology | 98 I ; | 38:329-3 |

3. Bean WJ, Rodan BA. Hepatic cysts: treatment with alcohol. Am J Roentgenol I 985; I 44:23741.

4. Solbiati L, Giangrande A, De Pra L, Bellotti E, Cantu P, Ravetto C, et al. Percutaneous ethanol injection of parathyroid tumors under US guidance: treatment for secondary hyperparathyroidism. Radiology 1985; I 55:607-I0.

5. Livraghi T, Salmi A, Bolondi L, Marin G, Arienti V. Small hepatocellular carcinoma: percutaneous alcohol injection: results in 23 patients. Radiology 1988; 168:3 |3-7.

6. Livraghi T, Festi D, Monti F, Salmi A, Vettori C. US-guided percutaneous alcohol injection of small hepatic and abdominal tumors. Radiology 1986; 161:309-12.

7. Livraghi T, Paracchi A, Ferrari C, Bergonzi M, Garavaglia G. Treatment of autonomous thyroid nodules with percutaneous ethanol injection: preliminary results. Work in progress. Radiology 1990; 175:827-9.

8. Monzani F, Caraccio N, Goletti O, Lipollis PV, Casolaro A, Del Guerra P, et al. Five-year follow-up of percutaneous ethanol injection for the treatment of hyperfunctioning thyroid nodules: a study of 117 patients. Clin Endocrinol (Oxf) 1997; 46:9-15.

9. Monzani F, Lippi F, Goletti O, Del Guerra P, Caraccio N, Lippolis PV, et al. Percutaneous aspiration and ethanol sclerotherapy for thyroid cysts. J Clin Endocrinol Metab 1994; 78:800-2.
10. Papini E, Panunzi C, Pacella CM, Bizzarri G, Fabbrini R, Psicchio G, et al. Percutaneous ultrasound-guided ethanol injection: a new treatment of toxic autonomously functioning thyroid nodules? J Clin Endocrinol Metab 1993; 76:4II-6.

I I. Lippi F, Ferrari C, Manetti L, Rago T, Santini F, Monzani $F$, et al. Treatment of solitary autonomous thyroid nodules by percutaneous ethanol injection: results of an Italian multicenter study. J Clin Endocrinol Metab 1996; 81:3261-4

I2. Goletti O, Monzani F, Caraccio N, Del Guerra P, Lippolis PV, Pucciarelli M, et al. Percutaneous ethanol injection treatment of autonomously functioning single thyroid nodules: optimization of treatment and short term outcome. World J Surg 1992; 16:784-90.

13. Martino E, Murtas ML, Loviselli A, Piga M, Petrini L, Miccoli P, et al. Percutaneous intranodular ethanol injection for treatment of autonomously functioning thyroid nodules. Surgery 1992; I I 2: 1 161-5.

14. Bianchini EX, Stamato F, Ikejiri ES, Carneiro MC, Maciel RM, et al. Percutaneous ethanol injection therapy (PEI) in thyroid nodules. Proceedings of the I 2 th International Thyroid Congress, Kyoto, Japan; 22-27 October 2000. Kyoto: Japan Endocrine Society; 2000. p. 157.

15. Monzani F, Del Guerra P, Caraccio N, Casolaro A, Lippolis PV, Goletti O, et al. Appearance of Graves'disease after percutaneous ethanol injection for the treatment of hyperfunctioning thyroid adenoma. J Endocrinol Invest 1997; 20:294-8.

16. Paracchi A, Reschini E, Ferrari C, Ciocia G, Castellani M. Changes in radioiodine turnover in patients with autonomous thyroid adenoma treated with percutaneous ethanol injection. J Nucl Med 1998; 39:1012-6.

17. Miller JM, Zafar S, Karo JJ. The cystic thyroid nodule. Recognition and management. Radiology 1974; I 10:257-6 I

18. Clark OH, Okerlund MD, Cavalieri RR, Greenspan FS. Diagnosis and treatment of thyroid, parathyroid and thyroglossal duct cysts. J Clin Endocrinol Metab 1979; 48:983-8.

19. Zingrillo M, Torlontano M, Chiarella R, Ghiggi MR, Nirchio V, Bisceglia M, et al. Percutaneous ethanol injection may be a definitive treatment for symptomatic thyroid cystic nodules not treatable by surgery: five-year follow-up study. Thyroid 1999; 9:763-7.

20. Kobayashi A, Kuma K, Matsuzuka F, Hirai K, Fukata S, Sugawara M, et al. Thyrotoxicosis after needle aspiration of thyroid cyst. J Clin Endocrinol Metab 1992; 75:2 1-4.

Artigo recebido: 02/05/01

Aceito para publicação: 19/10/01 